\title{
Socio-Economic Profile of the Dairy Industry in Cagayan Valley: Potential Users of Green Technology
}

\author{
Ma. Teresa S. Alvarez ${ }^{1, *}$, Diosdado C. Cañete ${ }^{2}$ \\ ${ }^{1}$ Department of Business Administration, Isabela State University, Echague, Isabela, Philippines \\ ${ }^{2}$ AgriBusiness and Agricultural Economics, College of Agriculture, Isabela State University, Echague, Isabela, Philippines
}

Received August 30, 2021; Revised October 15, 2021; Accepted November 7, 2021

\begin{abstract}
Cite This Paper in the following Citation Styles
(a): [1] Ma. Teresa S. Alvarez, Diosdado C. Cañete, "Socio-Economic Profile of the Dairy Industry in Cagayan Valley: Potential Users of Green Technology," Universal Journal of Agricultural Research, Vol. 9, No. 5, pp. 200 - 207, 2021. DOI: 10.13189/ujar.2021.090507.
\end{abstract}

(b): Ma. Teresa S. Alvarez, Diosdado C. Cañete (2021). Socio-Economic Profile of the Dairy Industry in Cagayan Valley: Potential Users of Green Technology. Universal Journal of Agricultural Research, 9(5), 200 - 207. DOI: 10.13189/ujar.2021.090507.

Copyright $\odot 2021$ by authors, all rights reserved. Authors agree that this article remains permanently open access under the terms of the Creative Commons Attribution License 4.0 International License

\begin{abstract}
Dairy farming plays a vital role in the social and economic livelihood of the farmer households and cooperatives in the Cagayan Valley. For the adoption of new technologies such as greening technology in dairy production, profiling of the dairy farm is an important factor in developing the assessment of the viability of the green tech to be adopted by the farmers as a means to increase their productivity and efficiency in farming. By considering this aspect, the study was undertaken in the Cagayan Valley and the respondents were purposively selected. There were four cooperatives that represented the region, while 10 farmer households were also randomly selected. The data was collected using a predesigned interview schedule on-farm/site. Key informant interviews (KII) and focus group discussion (FGD) will be the means of gathering relevant information. The collected data was analysed using basic descriptive statistical methods such as frequency, percentage, proportions, average, and rating. The results indicate that the majority of the dairy farmers in the Cagayan Valley belonged to the aged group, with an average age of 54 and above, with a degree in college, and a high income of up to P15,001-above/monthly, which represents the large and medium-sized families. The majority of dairy farmers had at least 5 years of experience using green technology, and $60 \%$ of them had both cattle and carabao as dairy farm animals. The adoption rate of green technology using vermicomposting and using solar panels by both categories of respondents reveals that there is a potential market expansion for the implementation of
\end{abstract}

green technology for the dairy farming industry and for further improvement of the socio-economic status of the farmers and their stakeholders, which may lead to their embracing green tech culture. Adequate research and a contribution from the NGO's and government in this sector are essential to improve the living conditions of the farmers in Cagayan Valley.

Keywords Dairy Farming, Green Technology, Vermicomposting and Solar Tech

\section{Introduction}

The dairy area plays a multi-faceted part in the financial improvement of country family units. Animals' raising emphatically affects value regarding pay; and work and neediness decreases in provincial territories. Dairy is a significant aspect of farming development and is additionally considered as a possible area for trade income [4]. The dairy industry is a large-scale practice of breeding and raising cows for the sole purpose of using their milk for the production of food. There are many different products that come from the milk extracted on dairy farms. Most of these products become food for human consumption. Some of the most common products are milk, ice cream, butter, yogurts, and cheeses. Globally, there is an increasing demand for dairy products and the 
industry has a remarkable potential for growth [12].

There are four main types of dairy farms in the Philippines: individual smallholder producers (who consume and sell locally what they produce), smallholder cooperatives (who deliver their milk to a collection point for transport to a processing plant), commercial farms (which supply processors), and government farms (which supply school and rural community feeding programs) [14]. A significant amount of the Philippine fluid milk supply is Ultra High Temperature (UHT) milk reconstituted from imported milk powder because of the country's cold chain challenges and limited production, as reported by the USDA-Dairy and Products Annual report [23]. The dairy industry in the Cagayan Valley has shown potential for active market growth with the participation of different cooperatives which serve as co-operators for the dairy farmers. With the use of green technology such as biogas digesters, solar panels and water pumping, vermicomposting, and the use of e-vehicles, there is a possibility of increasing production efficiency, improving labor efficiency, and improving farm working conditions, as well as improving milk quality, in order to improve their economic performance.

There are approximately 264 million dairy cows living on dairy farms around the world. Those cows produce an average of 600 million tons of milk. According to the statistics report of the National Dairy Authority (2018) [20], the Cagayan Valley has an average of 115 and 82 Isabela animals on the milk line. It has a total of 2274 for Cagayan and 414 herds for the 27 cooperative co-operators in the region. There are between 8 and 180 farmers in Cagayan and the Province of Isabela.

New greening technologies in the dairy industry are slowly being integrated both at the farm level and in the dairy processing plant [8]. Source and channels of agriculture information are used by the beneficiaries. Under the influence of breeding and of improved nutrition and management, milk production and its quality have been considerably increased during the past 40 years [19]. On the other hand, this modernization entails the concentration of production on fewer farms of larger size since it requires an estimated $33 \%-55 \%$ of the total labor in dairy farms [21].

The efficient management of milking improves cost-effectiveness and animal welfare as well [10]. Green technology is often referred to as environmental technology or clean technology. Technology is an umbrella term for sustainable technologies which contribute to lowering our negative environmental impact on our planet while sustaining our economic power at the same time. Although green tech is a relatively new idea at this point in time, eventually in the future, this will become quite important since we have to unravel our environmental problems in order to assure a framework where we, as humanity, can use green tech as efficiently as possible to improve our ecological footprint on a global scale. There is a possibility of enhancing production efficiency, improving labor efficiency, and improving farm working conditions, as well as improving milk quality, with the use of green technology such as biogas digesters, solar panels and water pumps, vermicomposting, and the use of e-vehicles.

Dairy farming plays a pivotal role in the economy of our country. It helps in augmenting the food supply, generating employment and raising nutritional levels. Dairy farming represents one of the largest and fastest growing sectors. Dairy enterprise is a solution to many problems in agriculture, besides being an effective tool to improve the socio-economic condition of rural farmers [18]. Inadequate knowledge of modern dairy practices and marketing facilities deteriorates the socio-economic conditions of the dairy industry in the region. The best option for increasing dairy productivity is through the adoption of improved technologies such as green technology and efficient use of available resources [2].

The purpose of this study is to generate a data bank on the co-operators who are adopting green technologies in the Cagayan Valley. Benchmarking dairy farms and stakeholders in the region based on their profiles, as well as investigating the characteristics of co-operators/farmers who are adopting green technologies, increasing labor efficiency, and improving farm working conditions.

\section{Methodology}

The sample size is determined through random stratified sampling. The collection of data is based on the records of the National Dairy Authority for both the Isabela and Cagayan Valleys. The study included four cooperatives: the Nueva Vizcaya Livestock Farmers and Raisers Multi-Purpose Cooperative, the Samahan ng mga Overseas Filipino Workers (OFW) ng Santiago City, the Mabuhay Agriculture Cooperative, and the Malaya Development Cooperative. While there were 10 sample households that represented the dairy farmers in the region.

The sampled farms accounted for all types of farms typically operating in the region, from small family farms to modern ones including milk production, animal population and farm gate price. The survey was conducted from September 2020 to February, 2021 by means of a carefully designed questionnaire and the information gathered through personal interviews, which will take place on-farm/site. Key informant interviews (KII) and focus group discussion (FGD) will be the means of gathering relevant information.

Basic descriptive statistical methods such as frequency, percentage, proportions, and averaging and likert scale ratings were used for the data collected. 
The conceptual framework employs established methodological tools. First, the benchmarking of the dairy co-operators and sampled household dairy farmers engaged in green technologies to improve their farm operations, thus increasing productivity and efficiency. Second, the dairy practices, including their milk production, and also the level of their awareness of the benefits of green technology, including problems encountered during the adoption and implementation of the technology, are discussed.

\section{Results and Discussion}

\section{Profile of the dairy cooperatives as respondents who practiced green technology}

The respondents for these cooperatives represent the cooperating agencies that are actually practicing greening technology and applying it to their specific farm operations. There are four (4) cooperatives that are engaged in dairy production in the region that participate in this study. They were represented by three municipalities in the region, namely: Bambang, Nueva Viscaya, Santiago City, and Mallig, Isabela. The cooperatives that represent the respondents were the following: Nueva Vizcaya Livestock Farmers and Raisers Multi-Purpose Cooperative; Samahan ng mga OFW ng Stgo. City; Mabuhay Agriculture Cooperative and Malaya Development Cooperative. These cooperatives have been in existence for an average of 7 years, and their dairy farm animals are a combination of carabao and cattle. But most of the cooperating agencies have the carabao as their main dairy farm animal producer. The majority of cooperating agencies are up to date on green technology; some have solar installations for their water pumps, and the majority practice vermicomposting.

The Nueva Vizcaya Livestock Farmers and Raisers Multi-Purpose Cooperative is a multi-purpose cooperative with most farmer-raisers as members. The cooperative received various agricultural machinery, equipment, and facilities from the Department of Agriculture (DA) Cagayan Valley Regional Field Office (RFO), as well as the irrigation network held on September 4, 2021.The Samahan ng mga OFW ng Stgo. City founders are all ex-abroad and initially owned a dairy farm and a herd of cattle/cattle. This cooperative is now emerging as one of the top cooperatives in the city which offers various marketing activities. The Mabuhay Agriculture Cooperative and Malaya Development Cooperative is an agri-based cooperative. They were one of the top producers of dairy milk in the region. Aside from milk production, they are also involved in corn silage production and marketing.

Their awareness of green technology is a manifestation of their training and seminars they attended and participated in the programs sponsored by Isabela State University (ISU), DOST, and the LGU. The ISU, together with their partnership with DOST/DOE/DA, conducted a series of trainings related to the awareness and adoption of green technology to improve their farming system and increase their yield and performance. 
Profile of the dairy farmers as respondents who practiced green technology

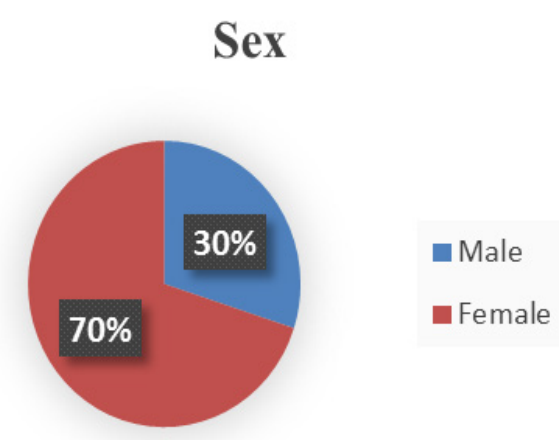

Income

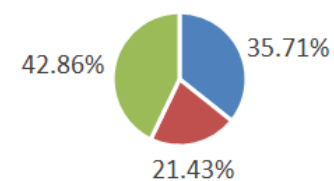

- Low income $(5,001-10,000)$

- medium Income $(10,001-15,000)$

- High Income (15,001- above)

\section{Educational Attainment}

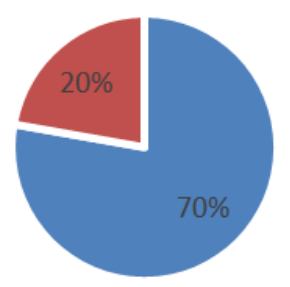

- High School - College

\section{Dairy Farm Animal}

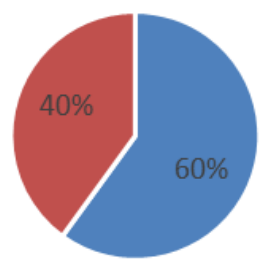

- Carabao - Cattle
Age

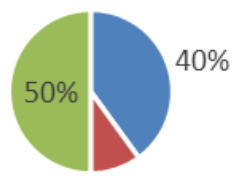

$10 \%$

- Young Age(48-50) - Middle Age (51-53)

- Old Age (54- above)

\section{Size of family}

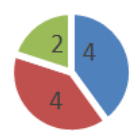

- small family (4 members)

- Medium Family (5-6 members)

- Large Family (more than 6 members)

\section{Years of Operation}

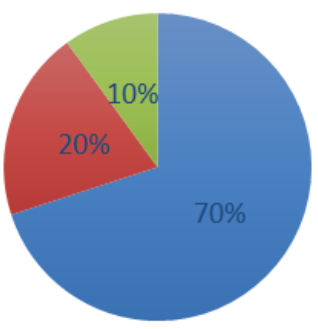

-1-5years $\square$ 6-10 years $\square 11$ years above

\section{Green tech practices}

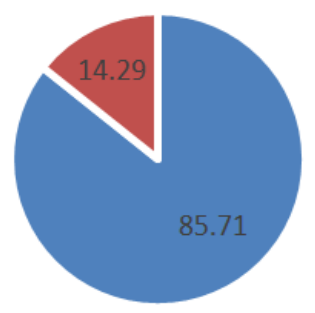

- Vermicomposting " Solar

Figure 1. Profile of the dairy farmers as respondents who practiced green technology

The figures presented the profile of the households engaged in greening technology. This also represents the area covered in the study.
Sex. The figure 1 depicts the sex of the respondents, with females accounting for $70 \%$ and males accounting for $30 \%$. This indicates that most of the households that take 
care of dairy farming are managed by female farmers. This shows that a farming job is not only for males but also for females. The main results found that local chicken farming is an activity under the responsibility of men with an average age of $41.95 \pm 10.84$ years old [16].

Age. The result shows that the majority of the age of the farmer respondents ranges from 54 and above, with 6 as a numerical value and categorized as old age, while 48-50 years of age as young age and 51-53 years of age as middle age have a numeral value of 3 and 1, respectively. This shows that most of the farmers are seniors and probably have matured while doing farming [17].

Income. Based on the results of the survey, most of the dairy farmers incurred a high income of 15001-and above, or 42.86 percent, while 33 Or 35.71 percent had a medium income of $10,001-15,000$ and 5 or 21.43 percent had a low income of 5,001-10,000, respectively [13].

Size of the family. The result shows that the average family size of a dairy farmer has an average of 2 children, or small family size, while other families have 3-4 children, or medium size, and 2 families with 6 children belong to a large family, respectively [8].

Educational Attainment. For this figure 1, it shows that 70 percent or 7 of them finished high school while 30 percent or 3 of them graduated from college. The probable reason for this might be that the majority of carabao/ cattle owners were from the middle and older age groups [5]. As supported in the study, only $22.2 \%$ of farmers had higher secondary or above education which is better than the findings of the previous study [9].

Years of operation. The result indicates that most of the respondents with a numerical value of 7 have 1-5 years of operating the farm, while 2 or 6-10 years, and 1 or 11 years and above, maximum operation.

Dairy Farm Animal. Most of the respondents have carabao as their main dairy farm animal, with a numerical value of 6 respondents, or 60 percent, while cattle are represented by 40 percent, or 4 households. There are also farmers who have both cattle and carabao as their dairy animals.

Practices in Green Technology. The respondents mostly practice vermicomposting, with 12 or 85.71 percent of practitioners, while 2 or 14.29 percent only use solar power. It has been noted that the two respondents who practice solar are the cooperatives of Malaya Development Cooperative, Mallig, and Samahan ng mga OFW ng Santiago. City, respectively. Most of the respondents appreciate vermicomposting as a means of increasing their production and maximizing their profits. Probably because it is cheaper than solar, installation is very expensive and costly. Despite the benefits, about $54 \%$ of farmers fed their cattle with concentrate but the recommended ration was not given [15]. Around $59 \%$ of the farmers fed their cattle traditional way.

\section{Awareness of the green technology for both cooperatives and dairy farmers}

The level of awareness of green technology was evident with the results in the figure 2 . The respondents are very much aware of green technology, whether it is through vermicomposting, electronic bicycle, and biogas digesters or through solar power, with 85.71 percent awareness and only 14.19 percent not aware. Farmers believe that through this technology, it can somehow improve their economic performance by increasing production efficiency, labor efficiency, and working conditions on the farm. Also, minimizing cost while maximizing profit and benefits.

\section{Awareness}

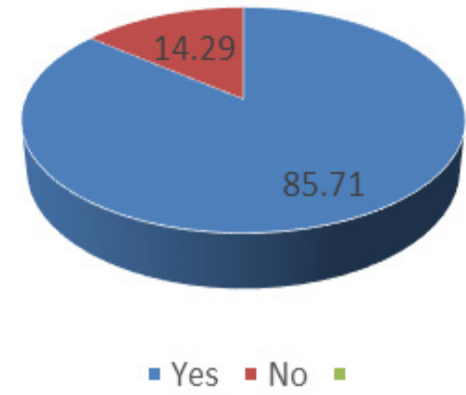

Figure 2. Awareness for the green technology by the farmer

\section{Level of awareness as to the nature of green technology}

Table 1 reveals the result of the response by the farmers. It shows their level of awareness as to the kind or nature of the green technology concerned. The majority of the responses show the highest level of awareness of the following: the use of green corn silage as feed for the dairy animals; the level of awareness of the use of vermi to compost the farm manure/dairy manure for compost production; and green dairy technologies as an environmentally friendly means of production. 13 or 92.86 percent are aware of the use of electronic tricycles for dairy product transportation, while 10 or 71.43 percent are aware of the use of solar-powered irrigation systems for green corn and forage production; 8 or 57.14 percent are aware of the use of bio-gas digesters for methane gas collection from animal manure and use as fuel in cooking, waste materials recycling in your Dairy operation, and be aware of the environmental laws of the country, respectively. 6 or 42.86 percent of MSMEs Dairy operations are aware of waste segregation for bio-degradable and non-bio-degradable materials. 
Table 1. Level of awareness as to the nature and Kind of Green Technology

\begin{tabular}{|l|c|c|}
\hline \multicolumn{1}{|c|}{ Nature and Kind of Green Technology } & $\begin{array}{c}\text { Frequency } \\
\text { n-14 }\end{array}$ & $\begin{array}{c}\text { Percentage } \\
\%\end{array}$ \\
\hline The level of awareness on the use of green corn silage as feed to the dairy animals. & 14 & 100 \\
\hline $\begin{array}{l}\text { The level of awareness on the use of solar powered irrigation system for green corn and forage } \\
\text { production. }\end{array}$ & 10 & 71.43 \\
\hline $\begin{array}{l}\text { The level of awareness on the use of bio-gas digester for methane gas collection from animal } \\
\text { manure and use as fuel in cooking. }\end{array}$ & 8 & 57.14 \\
\hline The level of awareness on the use of electronic tricycle for transportation of dairy products & 13 & 92.86 \\
\hline $\begin{array}{l}\text { The level of awareness on the use of vermi to compost the farm manure/dairy manure for } \\
\text { compost production }\end{array}$ & 14 & 100 \\
\hline Green dairy technologies are an environmental friendly & 14 & 100 \\
\hline $\begin{array}{l}\text { Waste segregation for bio-degradable and non-bio-degradable in your MSMEs Dairy } \\
\text { operation }\end{array}$ & 6 & 42.86 \\
\hline Aware on waste materials recycling in your MSMEs Dairy operation & 8 & 87.14 \\
\hline Aware on the environmental laws of the country & 87.14 \\
\hline
\end{tabular}

*multiple responses

The awareness level of green technology gives empirical evidence of improvement in both the environmental and economic or financial performance of the dairy farmer. They analyse the mechanism involved in each of the following channels of potential revenue increase or cost reduction owing to better environmental practices [1].

\section{Reasons for Adoption}

Table 2 presents the reasons for the adoption of green technologies, whether it's the installation of solar panels or water pumping, vermicomposting, or use of e-vehicles. The respondents had unified observations as to the usefulness of green technologies. Results indicated that the greening technology has been considerably helpful with the adoption of reducing energy bills, water usage, general office expenses, which resulted in a possible increase in production at a 100 percent rate. Followed by items “improving employees' health by providing a safe and healthy workplace", with a rate of 85.71 percent and, "Improving Disaster Recovery and Less Waste in the Workplace" with a rate of 71.43 percent, respectively." It is said that improving a company's environmental performance can lead to better economic or financial performance, and not necessarily to an increase in cost. [1]. Adopters of all improved technologies, management practices, and production systems other than grazing achieve higher milk production than do non-adopters. [4].

As cited by John Doerr, a businessman, "Green technologies - going green - is bigger than the Internet. It could be the biggest economic opportunity of the $21 \mathrm{st}$ century." [3].

Reduced energy bills. Green technology enables us to save plenty of renewable energy sources through energy-efficient devices, such as biogas digesters, the installation of solar panels and water pumping, vermicomposting, and the use of e-vehicles to increase production efficiency.

Reducing Water Use. Green technology may also enable us to use our natural resources more efficiently by water pumping using solar panel installation to reduce electricity costs.

Reducing General Office Expenses/Improving Budgets for Greater Income. Green technology allows us to reduce operating expenses while increasing income by using renewable energy for electricity and other office expenses. It also applies the recycling of resources efficiently and cutting the cost through this energy saving technology.

Increase in production. The green technology could possibly increase production by helping the co-operators and farmers to efficiently manage their resources at the dairy farm, applying recycling procedures, and maximizing the farm's potential to the fullest. Therefore, it would result in more animal-friendly production behavior.

Table 2. Reasons for the respondents' adoption of greening technologies

\begin{tabular}{|l|c|c|}
\hline \multicolumn{1}{|c|}{ Reasons for adopting } & $\begin{array}{c}\text { Respondents } \\
\mathbf{n - 1 4}\end{array}$ & $\begin{array}{c}\text { Percent } \\
\mathbf{\%}\end{array}$ \\
\hline Reduced Energy bills & 14 & 1.0 \\
\hline Reducing Water Use & 14 & 1.0 \\
\hline $\begin{array}{l}\text { Less Waste in the } \\
\text { Workplace }\end{array}$ & 10 & 71.43 \\
\hline $\begin{array}{l}\text { Reducing General Office } \\
\text { Expenses }\end{array}$ & 14 & 1.0 \\
\hline $\begin{array}{l}\text { Improving Budgets for } \\
\text { Greater Income }\end{array}$ & 14 & 1.0 \\
\hline $\begin{array}{l}\text { Improving Employee } \\
\text { Health }\end{array}$ & 12 & 85.71 \\
\hline $\begin{array}{l}\text { Improved Disaster } \\
\text { Recovery }\end{array}$ & 14 & 1.0 \\
\hline Increase in production & 10 \\
\hline
\end{tabular}

*Respondents were allowed to give multiple responses.

\section{Management Practices}

Table 3 shows the management practices of the farmer respondents. A majority of the farmers adopted the 
vermi-composting of farm material wastes; a rating of 10 or 71.43 percent for the item "practice silage/haylage making", a rate of 7 or 50.00 percent for the "use of e-transport," undefined rating of 4 or 28.58 percent" adopted solar panel construction and installation of water pumping/irrigation while no one adopt the construction of biogas to store methane gas for household use.

Better environmental practices may result in: (a) increased market access; (b) the sale of pollution-control technology; (c) risk management; (d) lower material, energy, and service costs; and (e) lower capital and labor costs [1].

Table 3. Green technologies adopted and practice dairy production.

\begin{tabular}{|c|c|c|}
\hline Green tech & $\begin{array}{c}\text { Frequency } \\
\mathbf{n - 1 4}\end{array}$ & $\begin{array}{c}\text { Percent } \\
\mathbf{\%}\end{array}$ \\
\hline silage/hylage making & 10 & 71.43 \\
\hline $\begin{array}{c}\text { solar panel } \\
\text { construction/installation of water } \\
\text { pumping/irrigation }\end{array}$ & 3 & 21.43 \\
\hline $\begin{array}{c}\text { construction of biogas to store } \\
\text { methane gas for household use }\end{array}$ & 0 & 0 \\
\hline $\begin{array}{c}\text { vermi-composting of farm } \\
\text { material wastes }\end{array}$ & 14 & 100 \\
\hline use of e-transport & 7 & 50.00 \\
\hline
\end{tabular}

*multiple response

\section{Problems encountered}

Table 4. Problems encountered by the respondents.

\begin{tabular}{|c|c|c|}
\hline Problems Encountered & $\begin{array}{c}\text { Frequency } \\
\mathbf{n - 1 4}\end{array}$ & $\begin{array}{c}\text { Percent } \\
\mathbf{\%}\end{array}$ \\
\hline Lack of funding & 10 & 71.43 \\
\hline $\begin{array}{c}\text { Lack Management } \\
\text { application }\end{array}$ & 4 & 28.58 \\
\hline $\begin{array}{c}\text { No Government } \\
\text { intervention (provide } \\
\text { financial assistance) }\end{array}$ & 8 & 57.14 \\
\hline $\begin{array}{c}\text { Less information } \\
\text { campaign }\end{array}$ & 3 & 21.43 \\
\hline $\begin{array}{c}\text { High cost of greening } \\
\text { technologies }\end{array}$ & 10 & 71.43 \\
\hline $\begin{array}{c}\text { Lack of Assistance/ } \\
\text { support }\end{array}$ & 10 & 71.43 \\
\hline High product cost & 4 & 28.58 \\
\hline Technical issues & 7 & 50.00 \\
\hline
\end{tabular}

*Respondents were allowed to give multiple responses.

Table 4 reflects the possible problems encountered by the co-operators and farmer households in implementing green technology on their respective farms. Based on the results of the survey, among the reasons cited by the 10 respondents, or 71.43 percent, are the lack of funding, the high cost of greening technologies, and lack of assistance/support. Of those, 8 or 57.14 percent reported no government intervention (possibly financial assistance), 7 or 50 percent reported technical issues, 4 or 28.58 percent reported a lack of management application and a high product cost, and 3 or 21.43 percent reported a lack of information campaign. As opined in the previous study, the unavailability of technology, lack of assistance and finance were mentioned as important constraints for technology uptake [11].

Though green technology is still quite immature, there is a potential for cooperatives and household farmers to consider this as an alternative means to increase their production and efficiency. Green tech will become a major industry in the future and new businesses that focus on this field right now might have great success in a few years.

\section{Conclusions}

Based on the summary of the findings, the following conclusions are drawn. The majority of the dairy farmers in the Cagayan Valley belonged to the aged group, with an average age of 54 and above, had college as their highest educational attainment, and had a high income of up to P15,001-above/monthly with large and medium-sized families. The majority of dairy farmers had at least 5 years of experience using green technology, and $60 \%$ of them had both cattle and carabao as dairy farm animals. The adoption rate of green technology using vermicomposting and using solar panels by both categories of respondents reveals that there is a potential market expansion for the implementation of green technology for the dairy farming industry and for further improvement of the socio-economic status of the farmers, which may lead to their embracing green tech culture.

As to the level of awareness as to the kind or nature of green technology, it shows the highest level of awareness of the following: such as the level of awareness of the use of green corn silage as feed for dairy animals; The level of awareness on the use of vermi to compost farm manure and dairy manure for compost production; and green dairy technologies as environmentally friendly; level of awareness on the use of electronic tricycles for transportation of dairy products; awareness of the use of solar-powered irrigation systems for green corn and forage production; level of awareness on the use of bio-gas digesters for methane gas collection from animal manure and use as fuel in cooking, Be aware of waste materials recycling in their dairy operation, and be aware of the environmental laws of the country, respectively. Only 6 percent, or 42.86 percent, are aware of waste segregation for bio-degradable and non-bio-degradable materials from dairy operations.

The management practices of the farmers show that the majority of them adopted the vermi-composting of farm material wastes; 71.43 percent practiced silage/haylage making; 50.00 percent use of e-transport; 28.58 percent adopted solar panel construction/installation of water pumping/irrigation; while no one adopted the construction of biogas to store methane gas for household use.

To the level of awareness of green technology, the response is overwhelming since the majority are aware of green technology and its effectiveness. However, when it 
comes to the problems encountered, it reveals that lack of funding, cost of the technology, and lack of support/assistance are reflected as hindrances that may lead to the full adoption and implementation of the green technology.

Benchmarking this data among dairy producers in the Cagayan Valley adopting green technology is essential for identifying co-operators who are practicing or adopting green technology. As evidenced by studies that enhance the contribution of technology to farmers' economic growth while also increasing their productivity, optimizing effective farming, the existence of this technology is quite beneficial.

\section{Acknowledgement}

The paper was a part of a project entitled "Greening Dairy Rural Industry Value Chain towards Economic and Environmental Sustainability in Cagayan Valley, R02" with the funding agency CHED-Kto12 DARE TO funded Project.

\section{REFERENCES}

[1] Ambec, S., \& Lanoie, P. (2008). Does it pay to be green? A systematic overview. Academy of Management Perspectives, 22(4), 45-62. https://doi.org/10.5465/amp.200 8.35590353

[2] Bhende, M.J. and Kaliranjan, K.P. 2007. Technical efficiency of major feed and cash crops in Karnataka. Indian Journal of Agricultural Economics, 34:207-219.

[3] John Doerr, May 13, 2009. 26 Key Pros and Cons of Green Technologies.

[4] Gangu Naidu Mandala, Meenakshi Verma, Anuj Verma, Suresh Sirisetti, Venkata Ramakrishna Rao Gandreti (2021). The Influence of Agricultural Farmers' Entrepreneurial Behavior on the Business Performance of Dairy Farmers in Andhra Pradesh. Universal Journal of Agricultural Research, 9(2), 57 - 61. DOI: 10.13189/ujar.2021.090204.

[5] Gulkari, K. D., Nethravathi, G., Podiyil, O.V. and Gade, Y. 2014. Profile analysis of dairy farm women in adoption of scientific practices. International Journal of Agricultural Extension, 2(3):159-163.

[6] M. Hall, J. Dixon, \& A. Gulliver, D. Gibbon. Farming Systems and Poverty IMPROVING FARMERS' LIVELIHOODS IN A CHANGING WORLD. 2001 .FAO and World Bank Rome and Washington D.C.

[7] Khanal AR, Gillespie J and MacDonald J .2010. Adoption of technology, management practices, and production system in US milk production. J. Dairy Sci. 93: 6012-6022.

[8] Kumar, V.; Prajapati, R. S.; Ghintala, A. and Singh, K. 2013. Source and channels of agriculture information used by the beneficiary farmers of NAIP-III. Gujarat Journal of Extension Education, 24: 35-38
[9] Mandal GK, Mandal MAS and Rahman MS. 2009. Production and marketing of milk in some selected areas of Serajgonj district. Bang. J. Agric. Econ. 32(1-2): 105-115

[10] Majewski1. E, Hamulczuk, M. Malak - Rawlikowska, A. M. Gębska, D. Harvey. January 2012. Cost-effectiveness assessment of improving animal welfare standards in the European Agriculture.

[11] Mekonnen H, Dehninet G and Kelay B. 2009. Dairy technology adoption in smallholder farm in Dejen district, Ethiopia. Tropical Animal Health and Production. Dordrecht : Springer Netherlands, Volume 42, Issue 2, pp 209-216

[12] Park, Y. W and Haenlein, G. F. W. Milk and Dairy Products in Human Nutrition: Production, Composition and Health. April 11, 2013. Wiley Online.

[13] Rani, D.V. 2009. Crisis management practices adopted in dairy farming by the farmers of Anand districts of Gujarat state (Unpublished) Ph. D. thesis, AAU, Anand.

[14] Sally Sally Bulatao. Philippines: Promoting dairy entrepreneurship through enterprise zones. National Dairy Authority, Manila

[15] Sathiadhas, R and Noble, D and Immanuel, Sheela and Jayan, K N and Sadanandan, Sindhu (2003) Adoption level of scientific dairy farming among IVLP farmers in the coastal agro ecosystem. Indian Journal of Social Research, 44 (3). pp. 243-250.

[16] Sendramampionona Rantenaina Ursule, Hantanirina Heliarisoa Isabelle , Rabearimisa Rivo Nirina , Zafitody Conscient, Bola Aldiel, Andriamananjara Andry, Randrianariveloseheno Arsène Jules (2020). Socio-economic Situation of Poultry Farmer and the Local Chicken Production System of the East-Coast of Madagascar. Universal Journal of Agricultural Research, 8(6), 185 - 201. DOI: $10.13189 /$ ujar.2020.080601

[17] Tekale, V.S. 2012. Participation of rural women in decision making process in agriculture. International Journal of Extension Education. 8:56-62.

[18] Vekariya, S.J, Kumar R. SAvsani H. H,Kotadiva C. R, Chaudhari G.M, Chatrabhuji B.B. Socio- Economic Profile of Madhari Dairy Farmers of South Saurashtra Region Curr Agri Res 2016: 4(2). doi: http://dx.doi.org/10.12944/CARJ. 4.2 .08

[19] Food and Agriculture Organization of the United Nations. Rome. 2017. The future of food and agriculture Trends and challenges.

[20] PSA 2018. Regional social and Economic Trends: Cagayan Valley

[21] The Environmental Impact of Dairy Production in The EU: Practical Options For The Improvement Of The Environmental Impact. Final Report. April 2000.

[22] United Nations (FAO-UN) Dairy Price Index. 2020

[23] USDA Foreign Agricultural Services: Dairy and Products Annual Report, October 14, 2020.

[24] Uddin MM. 2009. Feeding strategy for improving dairy cattle productivity in small holder farm in Bangladesh. Bang. J. Anim. Sci. 38: 67-85. 